\title{
Correction to: Signs and symptoms of acromegaly at diagnosis: the physician's and the patient's perspectives in the ACRO-POLIS study
}

\author{
Philippe Caron ${ }^{1} \cdot$ Thierry Brue $^{2} \cdot$ Gérald Raverot $^{3} \cdot$ Antoine Tabarin $^{4} \cdot$ Anne Cailleux $^{5} \cdot$ Brigitte Delemer $^{6}$. \\ Peggy Pierre Renoult ${ }^{7} \cdot$ Aude Houchard $^{8} \cdot$ Fatine Elaraki $^{8} \cdot$ Philippe Chanson $^{9,10}$
}

Published online: 31 October 2018

(c) The Author(s) 2018

\section{Correction to: Endocrine}

https://doi.org/10.1007/s12020-018-1764-4

The original version of this article unfortunately contained a mistake in corresponding author name as Philippe Chanson in the affiliation section.

The correct corresponding author name is Philippe Caron.
Open Access This article is distributed under the terms of the Creative Commons Attribution 4.0 International License (http://crea tivecommons.org/licenses/by/4.0/), which permits use, duplication, adaptation, distribution, and reproduction in any medium or format, as long as you give appropriate credit to the original author(s) and the source, provide a link to the Creative Commons license, and indicate if changes were made.
The online version of the original article can be found online at https:// doi.org/10.1007/s12020-018-1764-4.

$\triangle$ Philippe Caron

caron.p@chu-toulouse.fr

1 Hôpital Larrey, Toulouse, France

2 Aix-Marseille University, INSERM, MMG, AP-HM, Hôpital de la Conception, CRMR HYPO, Marseille, France

3 Groupement Hospitalier Est, Lyon, France

4 Hôpital Haut Lévêque-CHU de Bordeaux, Bordeaux, France

5 Rouen University Hospital, Endocrinology Unit, Inserm CIC-CRB
1404, F 76000 Rouen, France

7 CHU Bretonneau, Tours, France

8 Ipsen Pharma, Boulogne-Billancourt, France

9 Assistance Publique-Hôpitaux de Paris, Hôpital Bicêtre, Centre de Référence des Maladies Rares de l'Hypophyse HYPO, F94275 Le Kremlin-Bicêtre, France

10 Université Paris-Sud, Le Kremlin-Bicêtre, France 